\title{
TENDÊNCIAS DE INVESTIMENTOS NO ESTADO DE SÃO PAULO
}

\author{
Maria Cecília Comegno \\ Luís Antonio Paulino
}

\begin{abstract}
Resumo: A Pesquisa de Investimento no Estado de São Paulo acompanha as tendências econômicas pela captação das intenções de investimentos anunciados e, ao apresentar os dados desagregados espacial e regionalmente, permite a identificação e a localização de segmentos empresariais mais dinâmicos, particularmente aqueles de base tecnológica e de maior potencial de consumo.

Palavras-chave: investimento produtivo; atividade econômica; atração de negócios.
\end{abstract}

\begin{abstract}
The Survey of Investment in the State of São Paulo tracks economic trends as reflected by stated investment plans. The presentation of the loose data in spatial and regional terms allows for the identification of the most dynamic business sectors and their locations, especially those with a technological base and large consumer potential.
\end{abstract}

Key words: productive investment; economical activity; attraction of businesses.

V isando acompanhar os efeitos deletérios da guerra fiscal entre os Estados brasileiros sobre a capacidade de São Paulo de atrair novos investimentos e a do governo paulista de contra-arrestar tais efeitos, através do desenvolvimento de vantagens competitivas genuínas, o então governador Mário Covas, ainda em sua primeira gestão à frente do Executivo paulista, demandou à Secretaria de Ciência, Tecnologia, Desenvolvimento Econômico e Turismo a Pesquisa de Investimentos no Estado de São Paulo com o objetivo de monitorar as tendências do investimento produtivo no território paulista. Dada a necessidade de manter, de forma sistemática, um levantamento de dados que permitisse acompanhar as tendências setoriais e regionais das intenções de investimento, essa tarefa passou, em julho de 1998, a ser realizada pela Fundação Seade.

Se essa pesquisa nasceu num clima de guerra fiscal, como foi batizada a disputa entre governos estaduais pela atração de investimentos diretos, ela transformou-se no principal instrumento à disposição do governo e prefeituras paulistas para acompanhar a evolução das intenções de investimentos do setor privado no Estado de São Paulo e a resposta dos empreendedores aos esforços do go- verno e das prefeituras, no sentido de criar um ambiente favorável à tomada de decisões de investimento. Como trata de intenções de investimentos, ela é uma das únicas fontes de dados de tipo prospectivo e, nesse sentido, propicia informações importantes para as ações de planejamento público, em particular as do Plano Plurianual de Governo e as múltiplas ações desenvolvidas pela Secretaria de Ciência, Tecnologia, Desenvolvimento Econômico e Turismo, que requerem contínuo acompanhamento das tendências econômicas no Estado de São Paulo. Além disso, essa pesquisa, ao captar as tendências setoriais e espaciais e os tipos de investimento, proporciona a identificação de segmentos empresariais mais dinâmicos, particularmente aqueles de base tecnológica e maior potencial de crescimento, bem como os segmentos carentes de apoio governamental, mas com perspectivas de autosustentação a médio prazo. O conhecimento das intenções de investimentos permite orientar as políticas públicas, possibilitando a concentração de esforços e coordenação de recursos, com o objetivo de promover o desenvolvimento integrado do Estado nos planos regional e setorial.

A Pesquisa de Investimentos subsidia, igualmente, a ação do investidor privado. As decisões de investimento 
não são tomadas de maneira isolada. Dependem, na maioria das vezes, de investimentos anteriores em setores estratégicos como energia, infra-estrutura de transportes e telecomunicações. Uma decisão de investimento desencadeia outras complementares e ao longo da cadeia produtiva. Ao dar publicidade a essas decisões de investir, a pesquisa contribui para corrigir assimetrias de informação e dar maior eficiência aos mecanismos de mercado. As decisões de investir são tomadas sempre com base em expectativas de demanda futura que, se frustradas, implicam quase sempre prejuízos. A possibilidade de se entrar e sair de determinados mercados sem custos irrecuperáveis é apenas teórica, prevista na chamada teoria dos mercados contestáveis, mas sem contrapartida na realidade. Por isso, um ambiente institucional seguro, um horizonte claro e compromissos críveis dos parceiros públicos são ativos da maior importância para os empreendedores privados. A longo prazo, o que conta na atração de investimentos é a presença ou não de fatores favoráveis e facilitadores para a escolha da localização do investimento. Nesse sentido, a Pesquisa de Investimentos no Estado de São Paulo é um desses ativos que o governo paulista oferece também ao investidor privado. Ao dar maior transparência ao ambiente geral de negócios existente no Estado, aumenta o grau de visibilidade em relação ao futuro, incerto por sua própria natureza.

O investimento produtivo é uma variável-chave para conhecer o comportamento da economia. Num momento em que no Brasil se discute com intensidade o retorno ao desenvolvimento, mostra-se como variável bastante importante a ser monitorada tendo em vista auxiliar as decisões privadas de investimento. Dados recentemente divulgados pelo IBGE revelam que a taxa de investimento do país atingiu, no segundo trimestre deste ano, o menor índice trimestral em dez anos. A taxa, que mede a participação dos investimentos públicos e privados no Produto Interno Bruto (PIB), foi de 17,88\%. Restrições fiscais limitam o investimento público a não mais que $3 \%$ ou $4 \%$ do PIB e não há perspectiva de que esse quadro se altere substancialmente em futuro próximo. Desse modo, para que a taxa de investimento alcance os $25 \%$ do PIB, valor considerado, pela maioria dos analistas, necessário para que o Brasil retome uma trajetória firme de crescimento, o investimento privado precisa elevarse, no mínimo, em sete ou oito pontos percentuais nos próximos anos.

Além disso, pode-se também avaliar se a desconcentração da economia brasileira decorre exclusivamente da guerra fiscal ou de mudanças do seu padrão produtivo, bem como conhecer o movimento de alocação espacial das atividades produtivas, já apontado por vários estudos, na direção ao interior do Estado de São Paulo.

Apesar de uma certa descentralização da atividade produtiva brasileira, o Estado de São Paulo continua apresentando melhores condições para produzir, tais como, maior centro industrial, comercial e financeiro da América do Sul, melhor infra-estrutura de transporte, telecomunicações e energia do Brasil, maior concentração de centros de conhecimento tecnológico no país, alto nível de qualificação da mão-de-obra local, ampla rede de serviços de apoio, maior mercado consumidor e qualidade de vida de suas cidades. De fato, o Estado de São Paulo permanece na liderança do ranking dos Estados brasileiros com maior captação de investimentos estrangeiros. Comparando os dados acumulados pela pesquisa realizada em todos os Estados brasileiros pela Simonsen Associados, nos períodos de 1995-2001 e 2002, a região Sudeste permanece liderando as intenções de investimento e, segundo Simonsen Jr., "os investimentos no Estado de São Paulo continuam altos em valor, mas em porcentual os de outras regiões cresceram rápido" (www.estadao.com.br, 24/9/2003).

A produção e a disponibilização permanentes de informações sobre as decisões dos investidores passam, assim, a ser instrumento fundamental para o acompanhamento da dinâmica econômica do Estado de São Paulo e para a formulação de uma estratégia de desenvolvimento do Estado, que permita ao poder público manter uma atitude pró-ativa em relação a esse processo de transformação, seja estimulando fatores e características que impulsionem tal desenvolvimento, seja se antecipando na eliminação dos gargalos que possam vir a dificultá-lo no futuro.

\section{METODOLOGIA DA PESQUISA}

A metodologia atualmente utilizada pela Fundação Seade para realizar o levantamento das intenções de investimentos no Estado de São Paulo, desenvolvida a partir daquela originalmente empregada pela Secretaria da Ciência, Tecnologia e Desenvolvimento Econômico SCTDE, consiste em captar diariamente as informações primárias - anúncios de investimentos privados - na grande imprensa (Folha de S.Paulo, O Estado de S.Paulo), em publicações especializadas (Gazeta Mercantil, Diário do Comércio \& Indústria, Valor Econômico, inclusive nos 
sites desses jornais) e nas versões on-line de diversos jornais das regiões do Estado, de modo a abranger todas as regiões administrativas. Uma vez coletada a notícia, é feito um levantamento em listas telefônicas para o pré-cadastramento das empresas. Com o objetivo de confirmar a veracidade das informações divulgadas pela imprensa e para se obterem outros dados, é efetivada consulta às empresas por telefone, fax e/ou e-mail, com base em um questionário contendo as seguintes questões: valor a ser investido; tipo de investimento (implantação, ampliação, modernização); origem do capital (nacional ou estrangeira); município onde será realizado o investimento (são considerados apenas aqueles localizados no Estado de São Paulo); e complementação ou correção das informações cadastrais da empresa. Depois de confirmados, os dados são consistidos com as informações disponíveis para evitar dupla contagem e para eliminar os anúncios de investimentos referentes a transferências de patrimônio através de privatizações e de fusões de empresas privadas, marketing, treinamento de recursos humanos, investimentos no mercado de capitais, compra de bens duráveis, construção de imóveis residenciais e feiras, congressos, leilões e outros eventos. Todos os dados consistidos são organizados segundo a Classificação Nacional de Atividades Econômicas - CNAE e por região administrativa e de governo. Os valores anunciados em reais são convertidos para dólares pela taxa de câmbio média do mês em que foi publicado o anúncio. Em seguida, as informações são digitadas no banco de dados e mensalmente são emitidos relatórios em que os investimentos anunciados são totalizados e classificados por setor de atividade e região do Estado.

Deve-se ressaltar que o objetivo desta pesquisa é coletar apenas os anúncios de investimentos produtivos, ou seja, aqueles que, uma vez realizados, aumentarão a capacidade produtiva da economia, passando a contribuir para o crescimento da produção de bens e serviços e, conseqüentemente, para a geração de empregos em caráter permanente. Dessa forma, estão excluídos da coleta todos os investimentos anunciados na construção de imóveis residenciais. Destaca-se, ainda, que, atendendo a recomendações da ONU e do próprio IBGE para o cálculo da taxa de investimento do setor privado nas contas nacionais, as empresas estatais, por ofertarem bens e serviços no mercado segundo a mesma lógica das empresas privadas, foram equiparadas a estas para efeito da coleta de anúncios de investimentos.

\section{PRINCIPAIS TENDÊNCIAS}

Nos últimos quatro anos a economia paulista, não diferentemente da brasileira, apresentou dois movimentos do ponto de vista da atração de investimentos. O primeiro, que vem no esteio dos processos de privatização e de abertura da economia (1999-2001), caracterizou-se por uma forte atração de investimentos. É importante destacar que, apesar dos acontecimentos que abalaram a economia mundial e latino-americana ao longo de 2001 (crise na Bolsa de Nova York e recessão nos Estados Unidos, atentados terroristas de 11 de setembro, crise na Argentina), provocando uma expectativa de queda de intenções de investimentos produtivos anunciados pelas empresas privadas, a economia paulista manteve praticamente a mesma capacidade de atração de investimentos.

\section{GRÁFICO 1 \\ Anúncios de Investimentos \\ Estado de São Paulo - 1999-2002}

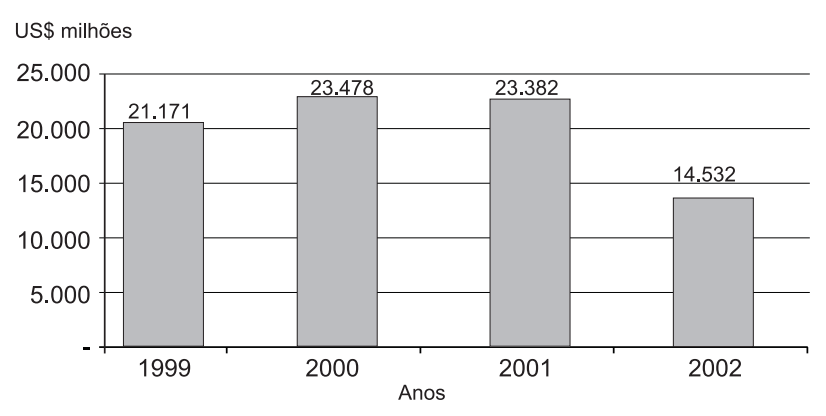

Fonte: Fundação Seade.

Já o segundo movimento, ocorrido em 2002, representou a queda de $38,28 \%$ nos anúncios de investimentos, refletindo certamente as conjunturas internacional e nacional desfavoráveis ao investimento produtivo. No âmbito internacional, 2002 foi um ano de contração de investimentos, com reflexos negativos sobre a economia brasileira. Basta lembrar a expectativa criada pelo recrudescimento dos conflitos internacionais no rastro dos atentados terroristas de setembro de 2001, os escândalos corporativos ocorridos na Europa e nos Estados Unidos, que levaram muitos investidores a descobrirem de forma amarga que seu dinheiro não estava em aplicação tão segura quanto imaginavam, e o baixo crescimento da economia mundial (2,4\% nos EUA e 0,9\% na EU). Esses fatos pro- 
vocaram um brutal recuo no fluxo de investimento direto estrangeiro em todo o mundo e particularmente para a América Latina (redução de $42 \%$ em 2002). No Brasil, não foi diferente: baixo crescimento da economia em 2002 $(1,5 \%)$, falta de recursos de investimentos estrangeiros ingresso de US\$ 16,6 bilhões, valor 26\% inferior aos US\$ 22,5 recebidos em 2001 - e aumento da incerteza associada ao processo eleitoral.

\section{Tendências Setoriais}

Pela análise da distribuição setorial, observa-se que, entre 1999 e 2002, houve predominância dos anúncios de investimentos voltados para a indústria, trajetória que só foi interrompida em 2001, quando foram superados pelos serviços, impulsionados basicamente por três subsetores: telecomunicações, transporte aéreo e atividades imobiliárias.

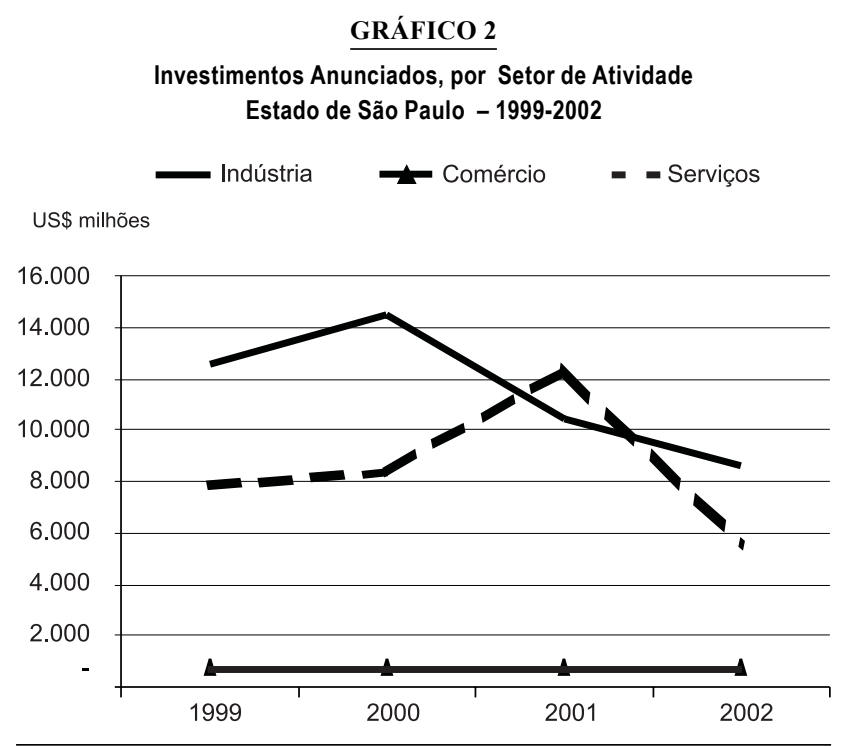

Fonte: Fundação Seade.

Do total dos investimentos anunciados entre 1999 e 2002, $55 \%$ destinaram-se à indústria, somando US $\$ 45,3$ bilhões, $42 \%$ foram para os serviços, num total de US $\$ 34,1$ bilhões, e o comércio ficou com $2,7 \%$ ou US $\$ 2,2$ bilhões.

$\mathrm{Na}$ indústria, o subsetor que apresentou maior volume de intenções de investimento foi o serviço industrial de utilidade pública de produção, transmissão e distribuição de eletricidade: US $\$ 11,6$ bilhões, o que representa 14,2\% do total dos anúncios de investimentos no período.

Essa posição de destaque explica-se por três fatores: a privatização do setor; a construção do gasoduto Bolívia-
Brasil; e o chamado "apagão", como ficou conhecida a crise de abastecimento no setor ocorrida em 2001, devido ao baixo nível dos reservatórios.

O setor de geração e distribuição de energia elétrica foi privatizado no final dos anos 90 . Desde então, as novas concessionárias privadas têm anunciado inúmeros investimentos para modernização e ampliação das atividades de geração e distribuição.

A construção do gasoduto Bolívia-Brasil, também no final dos anos 90, tinha por propósito mudar a matriz energética nacional, dando mais peso para a geração de energia a partir do gás natural, em face do esgotamento do potencial hídrico na região Sudeste. Tão logo o gasoduto, cujo traçado percorre praticamente todo o Estado de São Paulo, entrou em funcionamento, foram anunciados inúmeros investimentos para geração termelétrica em inúmeros municípios servidos pelo gás natural. Alguns deles, por questões ambientais e pela elevação do custo do gás após a desvalorização do real em 1999, ainda não foram viabilizados.

Por último, o chamado "apagão", como ficou conhecida a crise de abastecimento elétrico em 2001 por causa do baixo nível dos reservatórios das usinas hidrelétricas na região Sudeste e das deficiências nos sistemas de transmissão que interliga as diversas regiões do país, levou ao anúncio de novos investimentos, particularmente na área de geração termelétrica em função da oferta do gás natural boliviano. Não é de se estranhar, portanto, que o setor de eletricidade tenha estado, em todo o período, entre os que mais atraíram novos investimentos $\left(1^{\circ}\right.$ lugar em 1999 ; $3^{\circ}$ lugar em 2000; $1^{\circ}$ lugar em 2001; $2^{\circ}$ lugar em 2002).

A indústria automobilística foi o segundo subsetor industrial que mais anunciou novos investimentos no período. Foram US\$ 7,4 bilhões ou 9\% do total. Essa posição de destaque deve-se, principalmente, ao enorme peso desta indústria no parque industrial paulista e brasileiro. Há que se considerar ainda que, ao longo da década de 90, praticamente todas as grandes montadoras mundiais de automóveis que não estavam instaladas no Brasil resolveram fazê-lo, motivadas pelo potencial do mercado nacional e pelos processos de integração regional e hemisférica em curso. Isso levou a investimentos tanto por parte dos novos concorrentes quanto das empresas já estabelecidas, visando preservar sua liderança de mercado. Observe-se, entretanto, que no período considerado pode-se distinguir dois momentos distintos. Entre 1999 e 2000, ocorreram grandes anúncios de investimentos na indústria automobilística, tendo ocupado respectivamente o quarto e o pri- 
TABELA 1

Investimentos Anunciados, segundo Setores e Subsetores de Atividade Econômica Estado de São Paulo - 1999-2002

\begin{tabular}{|c|c|c|c|c|c|c|c|c|c|c|c|c|}
\hline \multirow[b]{2}{*}{ Setores e Subsetores de Atividade } & \multicolumn{4}{|c|}{ Posição } & \multicolumn{2}{|c|}{1999} & \multicolumn{2}{|c|}{2000} & \multicolumn{2}{|c|}{2001} & \multicolumn{2}{|c|}{2002} \\
\hline & 1999 & 2000 & 2001 & 2002 & $\begin{array}{c}\text { Valor } \\
\text { (US\$ } \\
\text { milhões) }\end{array}$ & $\%$ & $\begin{array}{c}\text { Valor } \\
\text { (US\$ } \\
\text { milhões) }\end{array}$ & $\%$ & $\begin{array}{c}\text { Valor } \\
\text { (US\$ } \\
\text { milhões) }\end{array}$ & $\%$ & $\begin{array}{c}\text { Valor } \\
\text { (US\$ } \\
\text { milhões) }\end{array}$ & $\%$ \\
\hline Total & & & & & $21.135,08$ & 100,00 & $22.978,03$ & 100,00 & $23.376,40$ & 100,00 & $14.431,40$ & 100,00 \\
\hline Transporte Terrestre & 38 & 40 & 6 & 1 & 25,79 & 0,12 & 19,63 & 0,09 & $1.675,48$ & 7,17 & $1.898,78$ & 13,16 \\
\hline Eletricidade, Gás e Água Quente & 1 & 3 & 1 & 2 & $3.958,96$ & 18,73 & $2.717,68$ & 11,83 & $3.551,92$ & 15,19 & $1.394,79$ & 9,66 \\
\hline Atividades Imobiliárias & 3 & 6 & 4 & 3 & $2.612,56$ & 12,36 & $1.238,45$ & 5,39 & $2.259,53$ & 9,67 & $1.273,21$ & 8,82 \\
\hline Papel e Celulose & 19 & 5 & 34 & 4 & 238,94 & 1,13 & $1.272,61$ & 5,54 & 38,27 & 0,16 & $1.148,67$ & 7,96 \\
\hline Refino de Petróleo e Álcool & 21 & 17 & 12 & 5 & 209,97 & 0,99 & 249,10 & 1,08 & 544,91 & 2,33 & $1.134,13$ & 7,86 \\
\hline Produtos Químicos & 5 & 4 & 11 & 6 & $1.515,50$ & 7,17 & $1.559,76$ & 6,79 & 548,84 & 2,35 & 967,60 & 6,70 \\
\hline Material Eletrônico e Equip. Comunicação & 6 & 18 & 16 & 7 & $1.097,38$ & 5,19 & 237,39 & 1,03 & 350,31 & 1,50 & 858,70 & 5,95 \\
\hline Aeronáutica (1) & 40 & 7 & 46 & 8 & 9,52 & 0,05 & $1.035,44$ & 4,51 & 2,29 & 0,01 & 807,44 & 5,60 \\
\hline Telecomunicações & 2 & 2 & 2 & 9 & $2.799,62$ & 13,25 & $4.028,55$ & 17,53 & $3.371,40$ & 14,42 & 574,70 & 3,98 \\
\hline Alimentos e Bebidas & 8 & 13 & 14 & 10 & 553,38 & 2,62 & 388,28 & 1,69 & 448,32 & 1,92 & 443,62 & 3,07 \\
\hline Automotiva & 4 & 1 & 9 & 11 & $2.120,54$ & 10,03 & $4.264,58$ & 18,56 & 611,83 & 2,62 & 400,65 & 2,78 \\
\hline Ativ. Aux. Transportes e Ag. Viagens & 17 & 8 & 17 & 12 & 300,89 & 1,42 & 904,54 & 3,94 & 230,71 & 0,99 & 383,99 & 2,66 \\
\hline Alojamento e Alimentação & 7 & 10 & 10 & 13 & 694,63 & 3,29 & 730,25 & 3,18 & 555,23 & 2,38 & 338,91 & 2,35 \\
\hline Varejo e Reparação de Objetos & 12 & 11 & 13 & 14 & 403,75 & 1,91 & 567,97 & 2,47 & 463,40 & 1,98 & 303,49 & 2,10 \\
\hline Minerais Não-Metálicos & 24 & 33 & 38 & 15 & 140,43 & 0,66 & 40,19 & 0,17 & 24,95 & 0,11 & 289,43 & 2,01 \\
\hline Metalurgia Básica & 15 & 9 & 8 & 16 & 346,87 & 1,64 & 760,47 & 3,31 & 624,98 & 2,67 & 277,03 & 1,92 \\
\hline $\begin{array}{l}\text { Limpeza Urbana e Esgoto } \\
\text { Atividades Recreativas, Culturais e }\end{array}$ & 35 & 49 & 32 & 17 & 29,48 & 0,14 & & & 42,60 & 0,18 & 264,63 & 1,83 \\
\hline Desportivas & 11 & 25 & 18 & 18 & 416,52 & 1,97 & 78,80 & 0,34 & 198,39 & 0,85 & 210,89 & 1,46 \\
\hline Educação & 33 & 30 & 19 & 19 & 40,54 & 0,19 & 44,25 & 0,19 & 171,24 & 0,73 & 157,18 & 1,09 \\
\hline Captação, Trat. e Distrib. de Água & 50 & 53 & 5 & 20 & - & - & - & - & $1.833,44$ & 7,84 & 130,34 & 0,90 \\
\hline Produtos Farmacêuticos (1) & 20 & 23 & 24 & 21 & 237,43 & 1,12 & 93,55 & 0,41 & 111,32 & 0,48 & 107,31 & 0,74 \\
\hline Atividades de Informática & 32 & 12 & 28 & 22 & 62,36 & 0,30 & 526,04 & 2,29 & 65,82 & 0,28 & 101,10 & 0,70 \\
\hline Saúde e Serviços Sociais & 18 & 19 & 29 & 23 & 246,75 & 1,17 & 180,44 & 0,79 & 65,18 & 0,28 & 84,50 & 0,59 \\
\hline Ativ. Juríd., Cont. e de Asses. Empresarial & 13 & 20 & 27 & 24 & 374,92 & 1,77 & 103,74 & 0,45 & 80,16 & 0,34 & 83,75 & 0,58 \\
\hline Com. e Rep. Automotores e Varejo & 26 & 36 & 23 & 25 & 11885 & 0.56 & 2968 & 0.13 & 12295 & 0.53 & 70.93 & 0.49 \\
\hline $\begin{array}{l}\text { decombustivel } \\
\text { Têxtil }\end{array}$ & $\begin{array}{l}\angle 0 \\
37\end{array}$ & $\begin{array}{l}30 \\
24\end{array}$ & $\begin{array}{l}23 \\
36\end{array}$ & $\begin{array}{l}25 \\
26\end{array}$ & $\begin{array}{r}118,85 \\
26,07\end{array}$ & $\begin{array}{l}0,56 \\
0,12\end{array}$ & $\begin{array}{l}29,68 \\
84,39\end{array}$ & $\begin{array}{l}0,13 \\
0,37\end{array}$ & $\begin{array}{r}122,95 \\
32,88\end{array}$ & $\begin{array}{l}0,53 \\
0,14\end{array}$ & $\begin{array}{l}70,93 \\
66,28\end{array}$ & $\begin{array}{l}0,49 \\
0,46\end{array}$ \\
\hline Intermed. Financ. (excl. seguros e prev. priv.) & 16 & 14 & 15 & 27 & 301,71 & 1,43 & 382,50 & 1,66 & 374,64 & 1,60 & 63,92 & 0,44 \\
\hline Borracha e Plástico & 10 & 21 & 20 & 28 & 441,58 & 2,09 & 102,04 & 0,44 & 162,22 & 0,69 & 53,27 & 0,37 \\
\hline Produtos de Metal (exclusive máq. e equip.) & 30 & 22 & 22 & 29 & 93,34 & 0,44 & 94,38 & 0,41 & 153,21 & 0,66 & 51,62 & 0,36 \\
\hline Máq. Escrit. e Equip. Informática & 25 & 26 & 25 & 30 & 133,05 & 0,63 & 59,51 & 0,26 & 101,98 & 0,44 & 50,42 & 0,35 \\
\hline Outros Equip. de Transporte & 48 & 31 & 40 & 31 & 2,40 & 0,01 & 43,47 & 0,19 & 22,47 & 0,10 & 45,03 & 0,31 \\
\hline Atacado & 36 & 37 & 35 & 32 & 28,97 & 0,14 & 28,94 & 0,13 & 36,64 & 0,16 & 43,36 & 0,30 \\
\hline Edição, Impressão e Gravações & 29 & 38 & 37 & 33 & 93,74 & 0,44 & 26,56 & 0,12 & 30,96 & 0,13 & 43,18 & 0,30 \\
\hline Pesquisa e Desenvolvimento & 46 & 52 & 55 & 34 & 3,70 & 0,02 & - & - & - & - & 42,58 & 0,30 \\
\hline Máquinas e Equipamentos & 14 & 34 & 30 & 35 & 347,15 & 1,64 & 39,80 & 0,17 & 64,52 & 0,28 & 40,74 & 0,28 \\
\hline Reciclagem & 42 & 50 & 41 & 36 & 7,11 & 0,03 & - & - & 19,80 & 0,08 & 39,22 & 0,27 \\
\hline Transporte Aéreo & 41 & 32 & 3 & 37 & 9,34 & 0,04 & 41,99 & 0,18 & $3.078,13$ & 13,17 & 29,34 & 0,20 \\
\hline Madeira & 22 & 16 & 50 & 38 & 156,55 & 0,74 & 371,22 & 1,62 & 0,51 & 0,00 & 25,21 & 0,17 \\
\hline Construção & 34 & 28 & 7 & 39 & 38,21 & 0,18 & 49,88 & 0,22 & 910,79 & 3,90 & 19,95 & 0,14 \\
\hline Atividades Associativas & 49 & 46 & 26 & 40 & 2,00 & 0,01 & 0,82 & 0,00 & 83,87 & 0,36 & 19,71 & 0,14 \\
\hline Máq., Aparelhos e Materiais Elétricos & 27 & 15 & 21 & 41 & 98,55 & 0,47 & 372,70 & 1,62 & 160,16 & 0,69 & 19,08 & 0,13 \\
\hline Móveis e Indústrias Diversas & 28 & 41 & 39 & 42 & 95,46 & 0,45 & 19,35 & 0,08 & 24,27 & 0,10 & 16,49 & 0,11 \\
\hline Vestuário e Acessórios & 53 & 45 & 44 & 43 & - & - & 1,42 & 0,01 & 4,40 & 0,02 & 16,28 & 0,11 \\
\hline Extração de Carvão Mineral & 51 & 54 & 56 & 44 & - & - & - & - & - & - & 11,34 & 0,08 \\
\hline Serviços Pessoais & 45 & 44 & 42 & 45 & 3,93 & 0,02 & 2,61 & 0,01 & 13,96 & 0,06 & 9,36 & 0,06 \\
\hline Aluguel Veíc., Máq. e Equip. e Obj. Pessoais & 47 & 47 & 33 & 46 & 2,72 & 0,01 & 0,08 & 0,00 & 41,33 & 0,18 & 4,95 & 0,03 \\
\hline Agropecuária e Pesca & 23 & 27 & 31 & 47 & 146,15 & 0,69 & 52,21 & 0,23 & 51,45 & 0,22 & 4,84 & 0,03 \\
\hline Seguro e Previdência Privada & 54 & 29 & 49 & 48 & - & - & 45,89 & 0,20 & 0,78 & 0,00 & 3,66 & 0,03 \\
\hline $\begin{array}{l}\text { Couro e Calçados } \\
\text { Equip. Médicos, Ópticos, de Automação }\end{array}$ & 39 & 42 & 48 & 49 & 13,38 & 0,06 & 18,47 & 0,08 & 1,39 & 0,01 & 3,37 & 0,02 \\
\hline e Precisão & 31 & 39 & 43 & 50 & 74,20 & 0,35 & 23,45 & 0,10 & 5,46 & 0,02 & 2,28 & 0,02 \\
\hline Ativ. Aux. Intermediação Financeira & 43 & 35 & 52 & 51 & 5,19 & 0,02 & 33,91 & 0,15 & 0,22 & 0,00 & 0,15 & 0,00 \\
\hline Transporte Aquaviário & 55 & 55 & 45 & 52 & - & - & - & - & 4,30 & 0,02 & - & - \\
\hline Fumo & 52 & 43 & 47 & 53 & - & - & 11,06 & 0,05 & 2,19 & 0,01 & - & - \\
\hline Extração de Minerais Não-Metálicos & 44 & 51 & 51 & 54 & 5,00 & 0,02 & - & - & 0,32 & 0,00 & - & - \\
\hline Outras Atividades & 56 & 56 & 53 & 55 & - & - & - & - & 0,08 & 0,00 & - & - \\
\hline Extração de Minerais Metálicos & 9 & 48 & 54 & 56 & 450,00 & 2,13 & - & - & - & - & - & - \\
\hline
\end{tabular}

Fonte: Fundação Seade.

(1) Por se caracterizarem como de alta intensidade tecnológica, as indústrias aeronáutica e de produtos farmacêuticos foram desagregadas dos subsetores Outros Equipamentos e Produtos Químicos. 
meiro lugares no ranking geral dos setores que mais anunciaram investimentos. Já em 2001 e 2002, os anúncios de investimentos apresentaram uma queda expressiva $\left(9^{\circ} \mathrm{e}\right.$ $11^{\circ}$ lugares), reflexo da crise mundial no setor e, principalmente, do fato de os investimentos no Brasil, nos anos anteriores, terem, aparentemente, superestimado a demanda potencial existente.

A indústria química e a de papel e celulose foram, respectivamente, o terceiro e quarto subsetores industriais que fizeram mais anúncios de investimentos no período. A indústria química divide com a automobilística a liderança na produção industrial paulista. Durante o período em estudo, 2001 foi o único ano em que o setor não esteve entre os três setores da indústria que mais anunciaram investimentos no Estado de São Paulo. A indústria de papel e celulose, por sua vez, tem o ritmo de investimentos determinado apenas em parte pelo mercado interno, uma vez que é um setor muito voltado para exportação. Dessa forma, os anúncios de investimentos são condicionados, em grande medida, pelo comportamento do mercado internacional. Depois de realizar grandes investimentos no início da década de 90, com a crise asiática, em 1997, e sua repercussão mundial, os investimentos refluíram no final da década, ocupando a $19^{a}$ posição no ranking geral em 1999. Com a melhora do mercado mundial, em 2000 os investimentos voltaram, ocupando o quinto lugar no ranking geral. Em 2001, com a crise americana, os investimentos novamente regrediram para a $34^{\mathrm{a}}$ posição, voltando, em 2002, a figurar no quarto lugar.

O subsetor de material eletrônico e equipamentos de telecomunicações aparece em quinto lugar na lista dos setores que mais anunciaram intenções de investimento no Estado de São Paulo entre 1999 e 2002. O comportamento desse setor está intimamente relacionado com o setor de telecomunicações. Desse modo, no rastro do processo de privatização do setor no final da década de 90 , com enorme expansão do parque instalado de telefonia móvel e fixa, o setor de equipamentos experimentou uma grande expansão nos anúncios de investimentos, tendo ocupado, em 1999, a sexta colocação no ranking geral dos setores que mais investiram no país. Em 2000 e 2001, reflexo do fim das privatizações, da crise americana e dos escândalos corporativos envolvendo grandes conglomerados mundiais de telecomunicações, o setor entrou em refluxo, ocupando respectivamente a $18^{\mathrm{a}}$ e a $16^{\mathrm{a}}$ posições no ranking geral. Em 2002, os anúncios de investimentos retornaram aos patamares do final da década, impulsionados principalmente pelos fabricantes de telefones celu- lares para atender tanto ao mercado interno quanto à exportação, obtendo grande impulso em função do câmbio extremamente favorável nos últimos dois anos.

Os outros setores industriais que merecem destaque são o de refino de petróleo e álcool, metalurgia básica, captação, tratamento e distribuição de água, indústria aeronáutica e indústria de alimentos e bebidas, que ocuparam, respectivamente, a $6^{\mathrm{a}}, 7^{\mathrm{a}}, 8^{\mathrm{a}}, 9^{\mathrm{a}}$ e $10^{\mathrm{a}}$ posições entre os subsetores industriais no período analisado. Os investimentos da Petrobrás em refino de petróleo têm sido constantes no Estado de São Paulo, nas refinarias de Paulínia, Cubatão e São José dos Campos. O setor alcooleiro, depois de um período de crise em meados da década de 90 , retomou parcialmente os investimentos em função das medidas de incentivo do governo do Estado para o setor.

Os investimentos na captação, tratamento e distribuição de água são de responsabilidade quase exclusiva de uma empresa estatal, a Sabesp. Falta ainda um marco regulatório consistente para atração de investimentos privados para o setor, que certamente demandará grandes investimentos nos próximos anos, diante da perspectiva de escassez de fornecimento de água, principalmente na Região Metropolitana de São Paulo.

A indústria aeronáutica, embora afetada pela crise mundial do setor resultante dos atentados terroristas de 2001, vem apresentando um grande desempenho exportador, basicamente em função da Embraer, localizada em São José dos Campos. Essa empresa tem uma carteira de exportação de jatos regionais de vários bilhões de dólares e um programa de investimentos no Estado de São Paulo que, apenas nos quatro anos considerados, alcança quase US\$ 2 bilhões.

Finalmente, o subsetor de alimentos e bebidas tem presença difusa em todo o Estado de São Paulo e, seguramente, é o setor industrial com maior capacidade de geração de empregos. Por ser um setor mais intensivo em mão-de-obra do que em capital, tem figurado nos últimos anos em posições intermediárias quando se analisa o montante dos investimentos anunciados. É, contudo, por essas mesmas características, o setor que mais tem gerado empregos formais no interior do Estado, estando presente em praticamente todas as regiões do Estado. O bom desempenho exportador do setor agroindustrial brasileiro tem impulsionado esse subsetor em todo o interior do Estado de São Paulo.

Em serviços, o subsetor de telecomunicações foi o que, depois de eletricidade, mais atraiu investimentos no Estado de São Paulo entre 1999 e 2002. Foram anúncios de 
investimentos no valor de US\$10, 8 bilhões, o que representa $13,2 \%$ do total de investimentos anunciados no Estado de São Paulo, no período considerado. No ranking geral dos subsetores que mais atraem investimentos, manteve-se de 1999 a 2001 sempre em segundo lugar, tendo caído, em 2002, para a nona posição.

Tal desempenho está associado, por um lado, ao processo de privatização do setor iniciado em meados da década de 90 e, por outro, ao fato de o Estado de São Paulo possuir a mais densa rede de telecomunicações do país. A maior parte dos investimentos ocorreu no setor de telefonia, fixa e móvel, praticamente universalizando o acesso em todo o Estado de São Paulo. Também houve grandes investimentos em redes de fibras óticas que comunicam grande parte dos municípios paulistas entre si e com as demais grandes cidades do país. Os chamados serviços de valor adicionado no setor de telecomunicações, como o acesso à Internet por banca larga, também apresentaram grande impulso, estando disponíveis em todos os municípios do Estado. Os serviços de TV a cabo ou por miniparabólicas estão presentes em todos os 645 municípios paulistas.

Atividades imobiliárias corresponderam ao segundo segmento no setor de serviços que mais atraiu investimentos, respondendo por anúncios no valor de US\$ 7,4 bilhões, o que equivale a $9 \%$ do total dos investimentos anunciados no Estado de São Paulo, no período em questão. Esse desempenho do setor imobiliário deve-se basicamente a dois fatores: grande número de novos empreendimentos imobiliários de alto padrão tecnológico para instalação de escritórios, bancos e sedes de grandes empresas, principalmente na cidade de São Paulo, com sofisticados serviços de telecomunicações, informática, heliponto, etc.; e a enorme expansão de grandes shopping centers em praticamente todo o Estado de São Paulo, principalmente nos municípios de médio e grande portes. Mesmo em cidades tradicionais do interior do Estado, a praça central, geralmente a da Igreja Matriz, perdeu há muito para os shopping centers seu papel de centro de encontro e convivência social.

Transportes terrestre e aéreo foram os subsetores que ficaram, respectivamente, em terceiro e quarto lugares em volume de investimentos no setor de serviços. Enquanto o primeiro atraiu anúncios de investimentos no valor de US\$ 3,6 bilhões no período (4,4\% do total), o segundo registrou anúncios de US $\$ 3,2$ bilhões (3,9\% do total). No subsetor de transporte terrestre, a maior parte dos investimentos concentrou-se na capital e na Região Metropoli- tana de São Paulo. Os investimentos em Metrô e em redes de trens urbanos responderam pela maior parte dos anúncios. Ocorreram também investimentos, mas bem menos significativos, em serviços de ônibus urbanos. No setor de transporte aéreo, o auge foi em 2001, quando a disputa acirrada entre as duas maiores empresas do setor levou ao anúncio de grandes investimentos, principalmente na aquisição de novas aeronaves. Depois dos atentados de 11 de setembro de 2001, o setor aeronáutico entrou em crise mundial com reflexos sobre as principais empresas brasileiras. Os investimentos em 2002 caíram praticamente a zero.

O subsetor de alojamento e alimentação foi, entre os subsetores de serviços, o quinto em volume de investimento. Entre 1999 e 2002, foram anunciados investimentos de US\$2,3 bilhões, o que corresponde a $2,8 \%$ do total anunciado no Estado para o período. Os principais responsáveis são os grandes empreendimentos no setor hoteleiro, com a implantação das principais bandeiras do setor hoteleiro mundial não só na cidade de São Paulo, como também em número crescente de municípios do interior.

Houve também investimentos significativos em outras áreas de serviços, tanto pessoais quanto os prestados a empresas, destacando-se: atividades auxiliares de transportes e agências de viagens; intermediação financeira; atividades recreativas, culturais e desportivas; e atividades de informática.

\section{Distribuição Regional dos Investimentos}

Quando se observa a distribuição espacial dos anúncios de investimentos no período 1999-2002, chama a atenção a continuidade da expansão da mancha de concentração de investimentos para além das regiões contíguas à Região Metropolitana de São Paulo. De fato, nos últimos anos, o processo de reestruturação da indústria paulista provocou deslocamento de indústrias para o interior do Estado, sobretudo para as regiões de Campinas, São José dos Campos, Santos e Sorocaba, que já tinham tradição manufatureira e mão-de-obra qualificada. Somente em 2001, a RMSP ultrapassou o interior em volume de investimentos anunciados. Entretanto, se considerados aqueles anúncios localizados em diversos municípios - originários de empresas com atuação em mais de um município, sem especificação do investimento por localidade e que estão espalhados por todo o Estado - no período analisado, o interior tem mostrado uma força crescente na atração de investimentos. 
TABELA 2

Investimentos Anunciados

Estado de São Paulo - 1999-2002

\begin{tabular}{|c|c|c|c|c|c|c|c|c|}
\hline \multirow[b]{2}{*}{ Regiões } & \multicolumn{2}{|c|}{1999} & \multicolumn{2}{|c|}{2000} & \multicolumn{2}{|c|}{2001} & \multicolumn{2}{|c|}{2002} \\
\hline & $\begin{array}{c}\text { Valor } \\
\text { (US\$ milhões) }\end{array}$ & $\%$ & $\begin{array}{c}\text { Valor } \\
\text { (US\$ milhões) }\end{array}$ & $\%$ & $\begin{array}{c}\text { Valor } \\
\text { (US\$ milhões) }\end{array}$ & $\%$ & $\begin{array}{c}\text { Valor } \\
\text { (US\$ milhões) }\end{array}$ & $\%$ \\
\hline Estado de São Paulo & $21.171,36$ & 100,00 & $23.478,03$ & 100,00 & $23.381,90$ & 100,00 & $14.432,33$ & 100,00 \\
\hline RM de São Paulo & $8.301,78$ & 39,21 & $5.898,76$ & 25,12 & $9.860,49$ & 42,17 & $4.735,93$ & 32,81 \\
\hline Interior do Estado & $8.503,56$ & 40,17 & $11.785,60$ & 50,20 & $9.061,65$ & 38,75 & $8.721,72$ & 60,43 \\
\hline Demais Municípios (1) & $4.366,02$ & 20,62 & $5.793,67$ & 24,68 & $4.459,76$ & 19,07 & 974,68 & 6,75 \\
\hline
\end{tabular}

Fonte: Fundação Seade.

(1) Empresas com atuação em mais de um município, sem definição do investimento para cada município.

É preciso, entretanto, matizar a clivagem RMSP/interior, pois a designação genérica interior já não dá conta das múltiplas realidades existentes fora da Região Metropolitana de São Paulo. Vale lembrar que o interior abriga municípios de grande porte e até mesmo duas regiões metropolitanas (Baixada Santista e Campinas), ao lado de áreas rurais com baixo grau de desenvolvimento econômico, como o Vale do Ribeira. Considere-se, ainda, que a distribuição dos investimentos pelo interior do Estado não é uniforme, ao contrário, está fortemente concentrada nos municípios e regiões mais próximos da capital, configurando uma mancha que se estende num raio de cerca de 150 quilômetros da capital do Estado. É bem verdade que esta pesquisa tem captado, nos últimos dois anos, um certo alargamento desta mancha, com a inclusão de municípios e regiões não contíguas à Região Metropolitana de São Paulo no rol dos municípios com boa capacidade de atração de investimentos. O fato concreto a se observar é que esta mancha compreende o resultado de movimentos complexos. No caso da RMSP, há uma força centrífuga representada pelas deseconomias de aglomeração (poluição, trânsito, violência, custo de terreno, impostos, etc.), que tende a deslocar empreendimentos já existentes e a não atrair novos investimentos, e uma força centrípeta representada pelas economias de aglomeração (tamanho do mercado consumidor, oferta de mão-de-obra, rede de serviços, proximidade com clientes e fornecedores), que mantém os que já estão instalados e atraem outros. No caso do interior, há um movimento com sentido oposto. A qualidade de vida, o custo da mão-de-obra e a boa infra-estrutura de transporte e telecomunicações atraem novos empreendimentos para essas regiões. A distância dos principais mercados consumidores, dos fornecedores ou dos principais clientes atua no sentido oposto. Da interação dessas forças surge uma resultante que, em última instância, acaba por beneficiar aquelas regiões e cidades que não estão tão longe da RMSP a ponto de dificultar o acesso ao mercado, clientes e fornecedores, mas que permitem às empresas livrar-se dos seus graves problemas urbanos. Conclusão: o equilíbrio entre essas forças acaba por determinar o tamanho da mancha de concentração da atividade econômica e, portanto, dos investimentos. Deste modo, quanto maiores as deseconomias de aglomeração associadas à RMSP e quanto mais vantagens oferecidas pelas demais regiões em termos de infra-estrutura, estrutura produtiva e tamanho de mercado, maior disposição terão as empresas de ir cada vez mais longe da RMSP. Mantidas as tendências atuais, portanto, é de se esperar que essa mancha vá se espalhando a uma velocidade que dependerá, de um lado, da taxa de crescimento da economia e, de outro, da capacidade ou não do poder público de fazer frente aos graves problemas que afetam a metrópole vis-à-vis a capacidade das grandes cidades do interior de atrair novos investimentos sem degradar o meio ambiente e a qualidade de vida local.

O movimento de atração de anúncios de investimentos por regiões administrativas também indica que a rigor não houve uma mudança significativa no ranking das regiões. As cinco primeiras regiões em valor de anúncios de investimentos continuam a ser as mesmas desde 1999, com exceção do ano 2000, quando a Região Administrativa Central (São Carlos e Araraquara) ocupou a quarta posição, ultrapassando a Região Metropolitana da Baixada Santista e a Região Administrativa de Sorocaba, enquanto a região de São José dos Campos ocupou a segunda posição, passando a região de Campinas. Exceto naquele ano, a ordem tem sido exatamente a mesma, ou seja, a Região Metropolitana de São Paulo permanece em pri- 
TABELA 3

Investimentos Anunciados

Estado de São Paulo - 1999-2002

\begin{tabular}{|c|c|c|c|c|c|c|c|c|c|c|c|c|}
\hline \multirow[b]{2}{*}{$\begin{array}{l}\text { Regiões Metropolitanas e } \\
\text { Regiões Administrativas }\end{array}$} & \multicolumn{4}{|c|}{ Posição } & \multicolumn{2}{|c|}{1999} & \multicolumn{2}{|c|}{2000} & \multicolumn{2}{|c|}{2001} & \multicolumn{2}{|c|}{2002} \\
\hline & 1999 & 2000 & 2001 & 2002 & $\begin{array}{c}\text { Valor } \\
\text { (US\$ } \\
\text { milhões) } \\
\end{array}$ & $\%$ & $\begin{array}{c}\text { Valor } \\
\text { (US\$ } \\
\text { milhões) }\end{array}$ & $\%$ & $\begin{array}{c}\text { Valor } \\
\text { (US\$ } \\
\text { milhões) } \\
\end{array}$ & $\%$ & $\begin{array}{c}\text { Valor } \\
\text { (US\$ } \\
\text { milhões) }\end{array}$ & $\%$ \\
\hline Total & & & & & $21.171,36$ & 100,00 & $23.478,03$ & 100,00 & $23.389,30$ & 100,00 & $14.561,57$ & 100,00 \\
\hline RM de São Paulo & 1 & 1 & 1 & 1 & $8.301,78$ & 39,21 & $5.898,76$ & 25,12 & $9.867,89$ & 42,19 & $4.729,93$ & 32,48 \\
\hline RA de Campinas & 2 & 3 & 2 & 2 & $4.086,37$ & 19,30 & $3.816,76$ & 16,26 & $3.736,36$ & 15,97 & $2.797,48$ & 19,21 \\
\hline RA de São José dos Campos & 3 & 2 & 3 & 3 & $1.569,28$ & 7,41 & $4.635,95$ & 19,75 & $1.754,58$ & 7,50 & $2.702,74$ & 18,56 \\
\hline RM da Baixada Santista & 4 & 5 & 4 & 4 & $1.193,90$ & 5,64 & 654,07 & 2,79 & $1.361,33$ & 5,82 & 752,12 & 5,17 \\
\hline RA de Sorocaba & 5 & 6 & 5 & 5 & 953,70 & 4,50 & 651,01 & 2,77 & 698,74 & 2,99 & 558,20 & 3,83 \\
\hline RA de Araçatuba & 11 & 8 & 11 & 6 & 39,87 & 0,19 & 215,42 & 0,92 & 34,52 & 0,15 & 479,57 & 3,29 \\
\hline RA Central & 7 & 4 & 8 & 7 & 136,22 & 0,64 & $1.080,73$ & 4,60 & 86,07 & 0,37 & 191,37 & 1,31 \\
\hline RA de Bauru & 8 & 7 & 6 & 8 & 99,37 & 0,47 & 457,70 & 1,95 & 619,88 & 2,65 & 165,13 & 1,13 \\
\hline RA de Ribeirão Preto & 6 & 9 & 7 & 9 & 219,11 & 1,03 & 102,42 & 0,44 & 565,43 & 2,42 & 108,67 & 0,75 \\
\hline RA de São José do Rio Preto & 9 & 12 & 9 & 10 & 86,67 & 0,41 & 33,17 & 0,14 & 85,04 & 0,36 & 61,16 & 0,42 \\
\hline RA de Marilia & 10 & 11 & 10 & 11 & 77,45 & 0,37 & 53,52 & 0,23 & 66,12 & 0,28 & 56,18 & 0,39 \\
\hline RA de Franca & 13 & 13 & 14 & 12 & 13,20 & 0,06 & 14,67 & 0,06 & 8,64 & 0,04 & 37,40 & 0,26 \\
\hline RA de Barretos & 14 & 14 & 12 & 13 & 12,18 & 0,06 & 5,17 & 0,02 & 33,82 & 0,14 & 25,76 & 0,18 \\
\hline RA de Presidente Prudente & 12 & 10 & 13 & 14 & 16,24 & 0,08 & 65,02 & 0,28 & 10,22 & 0,04 & 8,86 & 0,06 \\
\hline RA de Registro & 15 & 15 & 15 & 15 & - & - & - & - & 0,90 & 0,00 & - & - \\
\hline Diversos Municípios (1) & & & & & $4.366,02$ & 20,62 & $5.793,67$ & 24,68 & $4.459,76$ & 19,07 & $1.887,00$ & 12,96 \\
\hline
\end{tabular}

Fonte: Fundação Seade.

(1) Empresas com atuação em mais de um município, sem definição do investimento para cada município.

meiro lugar, seguida pelas regiões administrativas de Campinas, São José dos Campos, Região Metropolitana da Baixada Santista e Região Administrativa de Sorocaba.

O bloco que compõe a mancha de concentração de investimentos formada pela Região Metropolitana de São Paulo e seu entorno (regiões administrativas de Campinas, São José dos Campos, Sorocaba e Região Metropolitana da Baixada Santista) respondeu por quase $74,0 \%$ dos anúncios de investimentos coletados entre 1999 e 2002. É nessa mancha que se concentra o parque industrial paulista, com diversas vantagens locacionais que favorecem a recente renovação industrial e, ao mesmo tempo, constituem fatores de atração de novas indústrias e de expansão daquelas existentes. Essa mancha mostra-se como um pólo receptor de grandes volumes de capital, mas também como destino para investimentos tecnologicamente de ponta pelas vantagens comparativas de proximidade ao grande mercado consumidor da metrópole, mão-de-obra qualificada, densidade da malha urbana, infra-estrutura de transporte, telecomunicações e energia, serviços sofisticados de apoio, grande complementariedade industrial e concentração de centros de conhecimento tecnológico. Nas demais regiões do Estado, chama atenção o fato de que várias delas mantêm-se ao longo período variando muito pouco a sua posição no ranking das regiões que registraram anúncios de novos investimentos, tais como Bauru, Ribeirão Preto, São José do Rio Preto, Marília, Franca, Barretos, Presidente Prudente e Registro. Outras, como Central e Araçatuba, destacam-se pela sua variação no ranking, pois a primeira recebeu, em 1999, importantes investimentos no subsetor automobilístico no município de São Carlos e a segunda, em 2002, em virtude de um grande investimento na construção de usina termelétrica no município de Andradina.

Maria Cecília Comegno: Socióloga, Coordenadora de Projetos de Gênero na Fundação Seade. Foi responsável pela Diretoria Adjunta de Produção de Dados desta Fundação (ccomegno@seade.gov.br).

Luís Antonio Paulino: Engenheiro, Analista da Fundação Seade (lpaulino@seade.gov.br). 